\title{
Autophagy, a Highly Regulated Intracellular System Essential to Skeletal Muscle Homeostasis - Role in Disease, Exercise and Altitude Exposure
}

\author{
Anthony M.J. Sanchez, Robin Candau, \\ Audrey Raibon and Henri Bernardi \\ Additional information is available at the end of the chapter \\ http://dx.doi.org/10.5772/60698
}

\begin{abstract}
Autophagy is an evolutionarily conserved intracellular system that selectively eliminates protein aggregates, damaged organelles, and other cellular debris. It is a self-cleaning process critical for cell homeostasis in conditions of energy stress. Autophagy has been until now relatively overlooked in skeletal muscle, but recent data highlight its vital role in this tissue in response to several stress conditions. The most recognized sensors for autophagy modulation are the adenosine monophosphate (AMP)-activated protein kinase (AMPK) and the mechanistic target of rapamycin (MTOR). AMPK acts as a sensor of cellular energy status by regulating several intracellular systems including glucose and lipid metabolisms and mitochondrial biogenesis. Recently, AMPK has been involved in the control of protein synthesis by decreasing MTOR activity and in the control of protein breakdown programs. Concerning proteolysis, AMPK notably regulates autophagy through FoxO transcription factors and Ulk1 complex. In this chapter, we describe the functioning of the different autophagy pathways (macroautophagy, microautophagy, and chaperonemediated autophagy) in skeletal muscle and define the role of macroautophagy in response to physical exercise, a stress that is well assumed to be a key strategy to counteract metabolic and muscle diseases. The effects of dietary factors and altitude exposure are also discussed in the context of exercise.
\end{abstract}

Keywords: Cachexia, Endurance exercise, Hypoxia, Proteolysis, Sarcopenia 


\section{Introduction}

Skeletal muscle exhibits remarkable adaptive capabilities in response to various stimuli such as loading conditions (resistance training, microgravity), contractile activity (electrical stimulations, endurance exercise), environmental factors (altitude exposure), or nutritional interventions. To access this great capacity, a plethora of quantitative and functional adaptations are involved. Changes in the size of adult muscle, in response to these external stimuli, are mainly due to the growth of individual muscle fibers rather than an increase in fiber number [1].

The control of muscle mass is dependent upon a balance between anabolic and catabolic processes. Hypertrophy is associated with increased protein synthesis, while atrophy is characterized by increased degradation of muscle proteins and/or a decrease in protein translation. The initiation of protein synthesis is mainly mediated by a signaling pathway in which the mammalian/mechanistic target of rapamycin complex 1 (MTORC1), a multiprotein complex composed of MTOR (mammalian/mechanistic target of rapamycin), RPTOR (regulatory-associated protein of MTOR), mLST8/G $\beta \mathrm{L}$ (MTOR-associated protein LST8 homolog), DEPTOR (DEP domain containing MTOR-interacting protein), and PRAS40 (proline-rich Akt substrate of $40 \mathrm{kDa}$ ) [2,3]. MTORC1 by phosphorylating its substrates S6K1 (ribosomal protein p70S6 kinase 1) and 4E-BP1 (eukaryotic translation initiation factor 4E-binding protein 1) controls skeletal muscle protein translation and hypertrophy [4-7]. The Insulin signaling pathway leads to the activation of MTORC1 through the activation of the kinases PI3K (phosphatidylinositol 3-kinase), PDK1 (phosphoinositide-dependent kinase-1), and Akt. Akt, also known as protein kinase B (PKB), inactivates tuberous sclerosis complex 1/2 (TSC1/2), promoting MTOR activation by Rheb-GTP [8-10]. Akt also phosphorylates and inactivates the glycogen synthase kinase $3 \beta$ (GSK3 $\beta$ ), resulting in the activation of the eukaryotic translation initiation factor 2B (eIF2B) and increased protein synthesis [5,11].

Muscle atrophy leads to a state of weakness and emaciation of the body, which is encountered, for example, in the terminal phase of certain diseases or chronic infections such as cancer, AIDS, diabetes, bacterial infections, and nerve degeneration [12]. Muscle atrophy is also observed during aging, immobilization, and stress or trauma to the muscle and is associated with increased proteolysis. Protein degradation is essentially modulated by two conserved pathways: the ATP-dependent ubiquitin-proteasome system and the autophagy pathways.

The first one has been particularly involved in the degradation process after the discovery of two E3 ubiquitin ligases (E3 ligases), MAFbx/atrogin-1 (muscle atrophy F-box) and MuRF1 (muscle RING finger-1), which are both overexpressed in various models of atrophy (fasting, cancer, diabetes, immobilization, and other stresses) $[13,14]$. The invalidation of these proteins confers a resistance to certain types of induced atrophy, suggesting a critical role in the catabolism for the ubiquitin-proteasome pathway [13]. The function of E3 ligases is to ubiquitinate specific proteins to target them for recognition by the $26 \mathrm{~S}$ proteasome where they are eliminated. Other E3 ligases like zinc-finger protein 216 (ZNF216), the mitochondrial E3 ubiquitin protein ligase 1 (Mul1), and the tripartite motif-containing protein 32 (Trim32) have been shown to play an important role in skeletal muscle atrophy [15-17]. 
The autophagy signaling, which constitutes the second pathway, is important for maintaining cell metabolism and organelle turnover. It involves the degradation of substrates by hydrolases into a vesicle called lysosome [18]. Recent evidence demonstrates cross talk and cooperation between the ubiquitin-proteasome system and autophagy $[19,20]$. The importance of this pathway in skeletal muscle was long much neglected, and autophagy was thought to be a nonselective degradation system. However, it is now well recognized that autophagy machinery is critical for muscle homeostasis and organelle turnover in response to cellular stress like physical exercise or hypoxia [21]. Importantly, the energy sensor AMPK (5'-adenosine monophosphate-activated protein kinase) has been involved in the regulation of both protein translation pathway and protein degradation systems, with a particular interest in the regulation of autophagy program for the last few years. The present chapter focuses on the role of autophagy in skeletal muscle homeostasis. We will describe the functioning of the autophagy signaling pathways (i.e., macroautophagy, microautophagy, and chaperone-mediated autophagy) and detail the regulation of macroautophagy by both AMPK and MTOR, with the final goal to discuss the potential applications of recent discoveries concerning autophagyrelated pathologies. The involvement of autophagy in response to physical exercise (acute and chronic exercise) and altitude exposure is thereafter discussed.

\section{Autophagy, an intracellular system that delivers cytoplasmic components to lysosome for degradation}

\subsection{The autophagy pathways}

\subsubsection{Description of the system}

Autophagy has been discovered during nutrient privation and can be referred to as "selfeating" as cells degrade their own constituents to maintain cellular homeostasis in response to various injuries like starvation and hypoxia and in pathological conditions, including cancer, muscular dystrophy, and neurodegenerative diseases. One purpose of the starvation-induced autophagy is to degrade materials to provide amino acids and free fatty acids in order to preserve metabolism and ATP levels when extracellular nutrients reach hazardous low levels [22]. Moreover, autophagy also eliminates protein aggregates as well as unwanted and dysfunctional organelles. The term autophagy embraces macroautophagy, microautophagy, and chaperone-mediated autophagy that we will describe hereafter.

Macroautophagy and microautophagy are conserved from yeast to humans, and these processes were originally described as bulk degradation mechanisms. However, these two processes can be selective for targeting different organelles, and we distinguish mitophagy selective for degradation of mitochondria; pexophagy, selective for degradation of peroxisomes; xenophagy, selective for degradation of intracellular bacteria and virus; reticulophagy, selective for endoplasmic reticulum; heterophagy, selective for substances taken in by phagocytosis; golgiphagy, selective for Golgi apparatus; ribophagy, selective for ribosomes; crinophagy, specific for the contents (proteins, peptides) of secretory granules; glycophagy, selective for glycogen; and lipophagy, selective for lipid droplets [23-29]. Among these different varieties of 
autophagy, mitophagy has been the most studied in the last decade, and this process involves notably two Parkinson's disease factors, the RING-between-RING E3 ligase Parkin and the mitochondrial kinase PINK1 (PTEN-induced putative kinase protein 1), PTEN being "phosphatase and tensin homolog" [30,31]. After mitochondrial potential depolarization, PINK1 promotes Parkin activation through phosphorylation of its ubiquitin-like domain [32]. In addition to these factors, the mitochondrial E3 ligase Mul1 can also be involved in mitophagy by the degradation of the mitochondrial fusion protein Mfn2 (mitofusin-2) and the stabilization of the dynamin-related protein 1 (DRP1), resulting in mitochondrial fragmentation [33].

Autophagy by providing a turnover of the cellular components plays a central role in the homeostasis of the cell. It is a key mechanism by which a starving cell reallocates nutrients from unnecessary to more-essential processes. Macroautophagy, microautophagy, and chaperonemediated autophagy lead cytoplasmic substrates inside lysosomes in which their contents are digested by a battery of acidic hydrolases [34]. Four essential ubiquitous proteases have been identified: the cathepsins B, D, H, and L $[35,36]$. High levels of these cathepsins are expressed in tissues exhibiting high rates of protein turnover like the kidney, spleen, liver, or placenta, while low concentrations of cathepsins are found in tissues with lower protein turnover as skeletal muscles [37-40]. Similar enzymatic properties were reported for different muscles, independent of their metabolic and contractile type. However, their concentrations differ according to the fiber type. Indeed, slow-twitch oxidative muscles exhibit higher levels of cathepsins than the fast-twitch glycolytic muscles [35], suggesting a more important activity of this system in oxidative muscle. This data is in agreement with the fact that oxidative muscles present a more important protein turnover and a greater translational activity than glycolytic muscles.

Although skeletal muscle expresses cathepsins B, D, H, and L, they play distinctive roles. During fusion of myoblasts into myotubes, several groups have reported an increase in the expression and activity of lysosomal cathepsins, in particular cathepsin B [41-46]. Several studies showed that the expression of cathepsin $\mathrm{L}$ is induced during various forms of skeletal muscle atrophy including starvation [12,36,47-49]. Increase in cathepsin D activity has been reported in muscles of dystrophic mice and chicken and in muscles of patients with Duchenne muscular dystrophy [35,50].

\subsubsection{Microautophagy}

Microautophagy is localized directly at the level of the lysosome which directly engulfs cytosol components by invagination, protrusion, and/or elimination of the lysosomal limiting membrane. It is implicated in the degradation of long half-life proteins in numerous cell types and does not respond to classical stimuli inducing chaperone-mediated autophagy and macroautophagy [51]. In contrast to macroautophagy, microautophagy has not been extensively studied in skeletal muscle, and its functions in muscle proteolysis have to be more characterized [35].

\subsubsection{Chaperone-mediated autophagy}

Chaperone-mediated autophagy (CMA) is a selective form of autophagy that has only been described in mammalian cells to date [52,53]. In this form of autophagy, only cytosolic proteins that possess the consensus pentapeptide Lys-Phe-Glu-Arg-Gln (KFERQ) are recognized. The 
KFERQ-like sequence is recognized by the heat-shock cognate protein of $73 \mathrm{kDa}$ (hsc73) then targeted to lysosomes for degradation. This targeting needs the binding of the complex protein substrates hsc73 to the lysosome-associated membrane protein type 2A (LAMP-2A) and to a multi-molecular chaperone complex including hsp40, hsp70, and hsp90 at the cytosolic side of the lysosomal membrane [54]. LAMP-2A is a glycoprotein present at the lysosomal membrane which acts as a CMA receptor. The substrates are then unfolded and translocated across the lysosomal membrane with the hsc73 protein. Unlike other forms of autophagy, CMA is very selective in substrate degradation and cannot eliminate organelles [55-57].

The use of an antibody directed to the KFERQ amino acid sequence substrates showed that proteins containing this sequence are conserved in skeletal muscle during starvation, while they are degraded in the liver and heart [58]. Moreover, the absence of consensus sequence in most myofibrillar proteins indicates that this degradation pathway is not implicated in their degradation. However, Nishino and colleagues showed that LAMP-2 deficiency is the primary defect in human Danon disease, a pathology characterized by myopathy and cardiomyopathy with massive accumulation of autophagic vacuoles $[59,60]$.Thus, as microautophagy, CMA has to be more characterized in the context of muscle atrophy.

\subsubsection{Macroautophagy}

Macroautophagy, often referred to as autophagy or autophagosome-lysosome system, is an evolutionarily conserved intracellular system that coordinates and oversees the degradation of damaged organelles as mitochondria, peroxisomes, or ribosomes, intracellular pathogens, and unused long-lived proteins [61]. More than 30 autophagy-specific genes (Atgs) have been identified and are known to facilitate the sequestration of cytoplasmic substrates into a doublemembrane vesicle called autophagosome or autophagic vacuole. Atgs are essential mediators of autophagy, by controlling the formation of the autophagosome. Autophagosome fuses with lysosome to form an autolysosome (also called autophagolysosome).

\subsection{Macroautophagy: Autophagosome formation}

\subsubsection{Initiation}

Macroautophagy (autophagy) is initiated in response to a multitude of factors including nutrient deprivation and oxidative stress. The activation of autophagy during muscle wasting was shown by the accumulation of autophagosomes in muscles of fasted transgenic GFP-LC3 mice [62]. Studies showed that during starvation-induced atrophy, FoxO3a (forkhead box class $\mathrm{O} 3 \mathrm{a})$ regulates the transcription of several Atgs, including Atg4B, LC3B (microtubuleassociated protein 1A/1B-light chain 3B), Beclin-1, Vps34 (vacuolar protein sorting 34)/PI3K class III, Gabarapl1 (GABA receptor-associated protein-like 1), Atg12, and Ulk2 (unc-51-like kinase 2) [63,64]. Initiation of the autophagy processes involves the activation of the unc-51like kinase 1 (Ulk1, also called Atg1 in yeast)/Atg13/FIP200/Atg101 and the Beclin-1/Vps34 complexes. These proteins operate in conjunction with several Atgs to mediate the assembly of the autophagosomal membrane [65-68]. Ulk1 also phosphorylates Beclin-1 at Ser-14 following amino acid withdrawal, and this stage is necessary for the Vps34 lipid kinase 
activation and full autophagy induction [69]. In yeast and mammalian cells, Atg1 or Ulk1 (respectively) activity is suppressed under nutrient-rich conditions by MTORC1 (phosphorylation of Ulk1 at Ser-757) [65,70-73]. In addition, MTOR inhibition and its subsequent dissociation from Ulk1 are critical for Beclin-1/Vps34 complex activation by Ulk1 [69].

\subsubsection{Maturation of autophagosomes}

The maturation and completion of the autophagic vacuole is facilitated by a ubiquitin-like conjugation-signaling cascade that culminates with the binding of phosphatidylethanolamine (PE) to the cytosolic form of LC3 (LC3-I) to form LC3-II. LC3, a mammalian homolog of yeast Atg8, is a protein with a molecular mass of $17 \mathrm{kDa}$ that is distributed ubiquitously in mammalian tissues. Two other LC3 homologs are $\mathrm{GABA}_{\mathrm{A}}$ receptor-associated protein (Gabarap) and Golgi-associated ATPase enhancer (GATE-16). LC3-phosphatidylethanolamine conjugate (LC3-II) is recruited to the autophagosomes [74,75]. LC3-II plays here a structural role that allows the elongation and the formation of the mature autophagosome. The mature autophagosome fuses with the lysosome to form an autolysosome (Fig.1). Concomitantly, LC3-II in autolysosomal lumen is degraded by lysosomal hydrolases; thus, turnover of the autophagosomal protein LC3-II reflects autophagic activity [76]. LC3 also interacts with the autophagy adapter p62/SQSTM1 (sequestosome 1), which contains multiple apparent protein-protein interaction domains. p62 binding to LC3 permits the entry of ubiquitinated cargo into the autophagosome [77]. In addition, the Atg12-Atg5-Atg16 complex plays an important role in the maximal promotion of LC3 lipidation and autophagy induction [78].

\section{MACROAUTOPHAGY}

Phagophore

Pre-autophagosome

Autophagosome

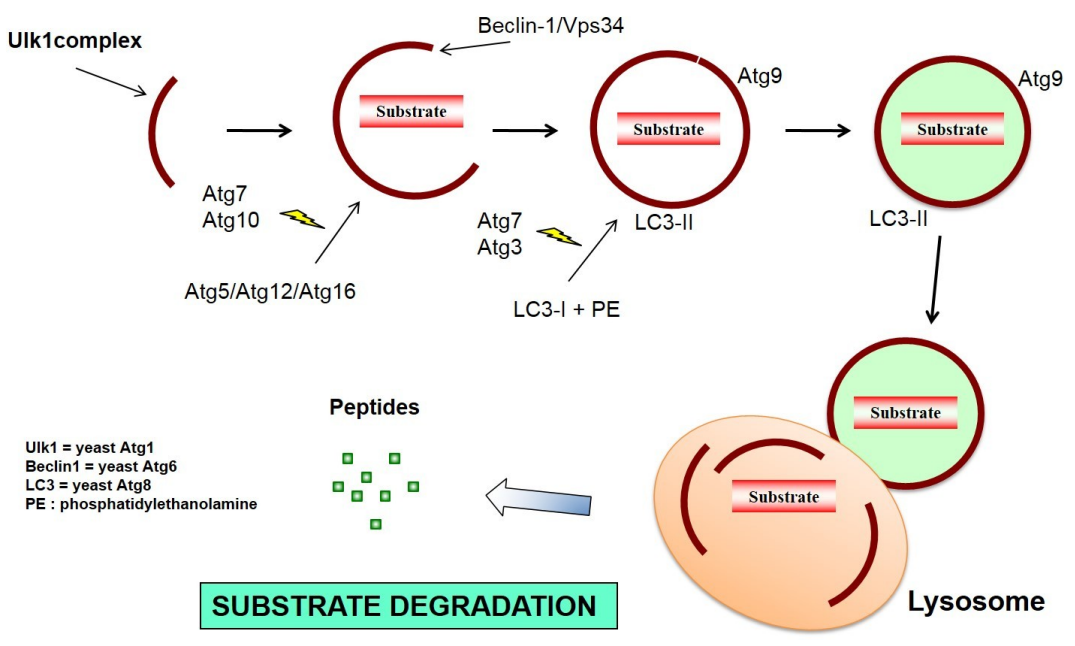

Figure 1. Processing of the macroautophagy system 


\subsection{Implication of autophagy in cell homeostasis and disease}

Autophagy plays a prominent role in the maintaining of cell homeostasis by selectively eliminating protein aggregates, damaged organelles, and other nonactive cellular debris $[79,80]$. This process is required for normal cellular function, but it is increasingly apparent that it can have both beneficial and detrimental effects on cells and tissues, depending on the origin of its activation [81]. Physiological function of basal autophagy in maintaining tissue homeostasis has been demonstrated in several tissues as the brain, liver, heart, striated muscle, intestine, pancreas, and adipose tissue [82-89]. Furthermore, exciting reports suggest that autophagy may contribute to counteract the deleterious effects of aging by limiting the deposition of aggregated proteins and damaged mitochondria [90-92]. By blocking apoptosis, autophagy preserves cell survival by providing endogenous metabolites when exogenous substrates are lacking [93]. Thus, at regular levels of activation, autophagy may represent the first step to restore homeostasis. However, when the autophagic capacity is submerged, apoptosis takes over [94]. Nevertheless, the relationship between autophagy and apoptosis appears to be extremely complex, and additional data are necessary to clarify the situation, especially in the context of disease.

In numerous pathologies as diabetes, obesity, cancer, heart failure, and neurodegenerative, infectious, and inflammatory disease, autophagy activity is affected $[34,95,96]$. For instance, it has been reported that the lack in Beclin-1 expression decreases autophagy flux and leads to increased risk of breast and prostate cancers [97]. However, the systematic beneficial effect of autophagy should be tempered. Thus, the role of autophagy in cancer is ambivalent, and this process can be involved in both the promotion and the prevention of this disease. In the first stage of the malignancy (i.e., tumor initiation), inhibition of autophagy may allow the growth of initial cancerous cells, and thus autophagy can act as a suppressor of cancer $[98,99]$. When cancer is established, transformed cells may need autophagy to survive, especially in nutrientlimiting condition [100]. In addition, for patient undergoing treatment such as chemotherapy, cancer cells could use autophagy to protect themselves from the stress induced by the therapy. Other reports indicate also that glycogen storage disease type II (also called Pompe disease) an autosomal recessive metabolic disorder - is a pathology attributable in part to mutations of Atgs. In this disease, muscle and nerve cells are damaged by an accumulation of glycogen into the lysosomes caused by a deficiency of the lysosomal acid alpha-glucosidase enzyme $[101,102]$. In many neurodegenerative disorders such as Parkinson's, Huntington's, and Alzheimer's diseases, accumulation of autophagic vesicles has been also observed [103-105]. Regarding Alzheimer's disease, it has been reported that Atg7 influences the accumulation of amyloid $\beta(\mathrm{A} \beta)$ peptides, resulting in aggregation into plaques in the brain [106]. In this model, autophagy seems to participate to the disease progression since it is involved in the generation of $\mathrm{A} \beta$ peptides.

In summary, by removing misfolded proteins and abnormal organelles, autophagy can be considered as a critical mechanism for cell protection. On the contrary, by destroying excessive fraction of cytosol and organelles, too high levels of autophagy represent a side mechanism responsible of the initiation of pathologies [94,107]. 


\subsection{The roles of autophagy in skeletal muscle}

Compared to other tissues like the liver or pancreas, autophagy in skeletal muscle exhibits a low protein turnover and a small size of autophagosomes. These peculiar characteristics have probably constituted a brake for the detection of autophagy in this tissue for a long time. Associated to the use of transgenic mice expressing LC3 fused with GFP, autophagy process can be now easily visualized [62]. Conversely to liver or pancreas in which autophagy is activated transiently for a few hours, in skeletal muscle, autophagy can be activated for several days [62]. As it was shown in other tissues, muscular autophagy is activated by nutrient deprivation or by the absence of growth factors [108].

Although it was reported that the mRNAs coding for Atgs are present in abundance in skeletal muscle [109], the role and the regulation of basal autophagy have been poorly characterized in this tissue until recently. In order to assess the function of autophagy in skeletal muscle, Masiero and colleagues performed experiments on mice deprived of the Atg7 gene, a gene necessary to the unfolding of the autophagy program $[86,110]$. Importantly, mice showed obvious signs of muscular weakness and atrophy exacerbated during ageing. Mice presented an accumulation of degraded proteins and free radicals, a deterioration of the internal cellular structures, and an activation of the apoptotic program. The authors clearly defined that inhibition of basal autophagy does not protect from skeletal muscle atrophy induced by denervation or starvation, but on the contrary, contributes to its degeneration. Similar muscle alterations have been obtained in muscle-specific Atg $5^{-/-}$mice [87], confirming the necessity to have regular autophagic flux in the cells, even during atrophy.

In many conditions varying from fasting, denervation, inactivity, microgravity, various pathologies as cancer, AIDS, sepsis, diabetes, cardiac failure, and myopathies, autophagy is overactive and pathologic, thus leading altered metabolism and muscle loss $[81,108,111]$. Contribution of autophagy to muscle loss begins to be clarified with the use of different animal models and innovative techniques. Inactivation of autophagic flux by LC3 silencing partially prevents FoxO3-mediated muscle atrophy [63] and atrophy caused by the expression of mutant SOD1 G93A in skeletal muscle [112]. In another model, atrophy induced by L-type calcium channel (DHPR) inactivation is linked to the expression of autophagic genes including LC3, Vps34, BNIP3 (BCL2/adenovirus E1B $19 \mathrm{kDa}$ protein-interacting protein 3), and cathepsin $\mathrm{L}$ (for the lysosome) [113]. During sepsis, an upregulation of autophagy was found in parallel to mitochondrial injury and decreased biogenesis, especially in locomotor muscles [114]. Reactive oxygen species overproduction by altered mitochondria is now considered as a critical signal for the promotion of skeletal muscle autophagy, thus finding an opening to practical prospects for treatment of disease [115]. Accordingly, antioxidant supplement can lead to an inhibition of skeletal muscle autophagy through a reduction of oxidative stress and an increase in antioxidant capacity [116]. Taken together, these recent results confirm that excessive activation of autophagy is a critical factor for muscle wasting determinism, and strategies attempted to control autophagy level will be promising.

Data concerning sarcopenia are also specific. Sarcopenia is an age-related loss of muscle mass and strength, which is associated with increased autophagy, apoptosis, and exacerbated proteolysis [117]. Elevated peroxisome proliferator-activated receptor-coactivator $\alpha$ (PGC-1 $\alpha$ ) expression in muscle during aging contributes to reduce the proteolytic activity associated 
with atrophy. In sarcopenia, attenuation of the degradative processes and the maintenance of mitochondrial function contribute to the preservation of muscle integrity [118].

In summary, as already described for cancer cells, autophagy in muscle is a complex process that can be, according to its activation level, beneficial or deleterious. During disease, the systematic question is to determine whether autophagy plays a protective function, has a causative role, or is a result of the disease process itself.

\section{AMPK and skeletal muscle autophagy}

\subsection{The AMP-activated protein kinase}

AMPK is a serine/threonine protein kinase highly conserved through evolution. AMPK is a heterotrimeric complex composed of a catalytic subunit (AMPK- $\alpha$ ) and two regulatory subunits (AMPK- $\beta$ and AMPK- $\gamma$ ). Humans have seven genes encoding AMPK subunits $(\alpha 1$, $\alpha 2, \beta 1, \beta 2, \gamma 1, \gamma 2, \gamma 3)$ that can form at least $12 \alpha \beta \gamma$ heterotrimers, increasing the diversity of its functions [119]. The catalytic $\alpha$ subunit contains the threonine phosphorylation site that upon phosphorylation leads to AMPK activation [120]. AMPK acts as a sensor of cellular energy status by regulating several intracellular systems including glucose and lipid metabolisms and mitochondrial biogenesis [121]. Thus, AMPK activation leads to increased glycolysis flux [122] and fatty acid oxidation [123-126] and on the contrary, to an inhibition of glycogenogenesis $[127,128]$ and cholesterol and fatty acid biosynthesis [129-131]. The enzyme also increases the expression of PPAR $\alpha$ (peroxisome proliferator-activated receptor $\alpha$ ) target genes and PGC-1 leading to mitochondrial biogenesis and enhanced oxidative metabolism of muscle cells $[132,133]$. AMPK is activated by a large variety of cellular signals that decrease cellular ATP levels and increase AMP in response to different kinds of stress like electricalstimulated muscle contraction, exercise, hypoxia, and heat shock or under conditions of nutrient deprivation $[124,134,135]$. The recognized enzymes in the regulation of AMPK under energy stress conditions are LKB1 (liver kinase B1), CaMKK (calmodulin-dependent protein kinase kinase), and TAK-1 (transforming growth factor beta-activated kinase 1).

\subsection{Regulation of skeletal muscle autophagy by AMPK}

The role of AMPK in protein turnover has been clearly defined in recent years. AMPK has been involved in the control of protein synthesis and the repression of skeletal muscle mass by inhibiting MTOR activity $[136,137]$ in two ways: AMPK phosphorylates TSC2 (tuberous sclerosis complex 2) at Thr-1227 and Ser-1345 and RPTOR at Ser-722 and Ser-792, leading to a reduction of MTORC1 activity. Several studies also showed that AMPK increases protein degradation through the modulation of the ubiquitin-proteasome and the autophagosomelysosome pathways $[138,139]$. AICAR (5-aminoimidazole-4-carboxamide-1- $\beta$-D-ribonucleoside, an AMPK activator) treatment increases the expression of the E3 ligases MAFbx/ Atrogin-1 and MuRF1 in muscles cells. In addition, increase of autophagic flux by AMPK has been reported in several muscle models as $\mathrm{C} 2 \mathrm{C} 12$ myoblasts, $\mathrm{C} 2 \mathrm{C} 12$ myotubes, and primary myotubes $[138,139]$. Two major signaling pathways were characterized in AMPK-induced muscular autophagy (Fig.2). 


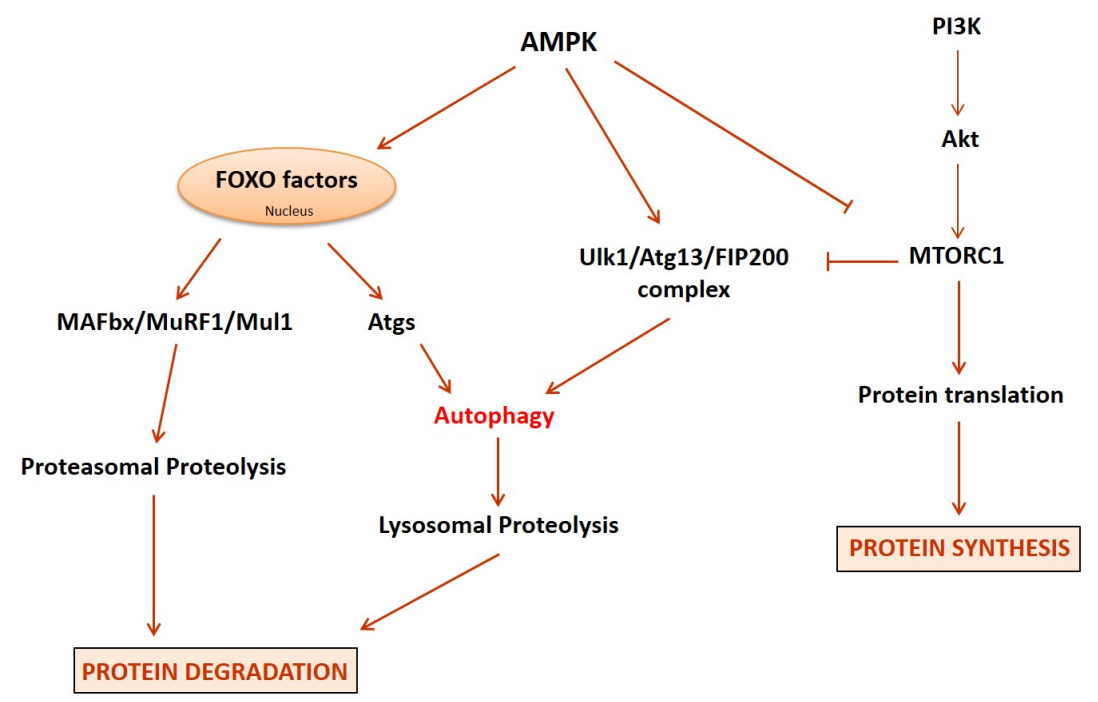

Figure 2. Role of AMPK in skeletal muscle protein turnover

The first one concerns the activation of the forkhead box class $\mathrm{O}$ proteins (FoxO), notably involved in the regulation of protein breakdown, energy metabolism, and mitochondrial turnover [140]. FoxO factors also play an important role in exercise-induced angiogenesis by limiting it during the first days of training program [141,142]. Activation of FoxO3a by AMPK leads to an increase in several Atgs expression, including LC3-II and Gabarapl1 that act as promoters of autophagosome fabrication [139]. AMPK directly interacts with FoxO3a and phosphorylates it on Ser-588, a residue known to lead to FoxO3a activation $[139,143]$. The upregulation of several Atgs by FoxO factors have been described in Drosophila larval fat body [144], mammalian cardiomyocytes [145], hepatocytes [146], and colorectal cancer cells [147]. Regarding the regulation of FoxO3a subcellular localization in muscle cells, while long treatments (i.e., $24 \mathrm{~h}$ ) with AMPK activators do not change FoxO3a nuclear content, an increase in the total protein level is notable after $30 \mathrm{~min}$. With a short time course (30 min-6 h), the activation of AMPK by AICAR leads to a relocalization of FoxO3a into the nucleus [139]. Tong and colleagues reported that AICAR treatment causes FoxO3a nuclear relocation through a decrease in FoxO3a phosphorylation at Thr-318/321 [148]. However, Greer and colleagues have reported an increase of FoxO3a transcriptional activity without any change in the nuclear content of the factor after AMPK activation by 2-deoxyglucose (2DG) in HEK293T cells [143]. These data strongly suggest that FoxO3a relocalization into the nucleus is not necessarily required to increase its transcriptional activity. A possibility is that AMPK may also control FoxO3a protein stability.

The second pathway involves modulation of the Ulk1 complex. A multiprotein complex composed of AMPK, MTORC1, Ulk1, FIP200, and Atg13 has been identified in muscle cells (Fig.3) [139]. These data fit with the model found in other cell types showing that, under basal 
conditions, MTORC1 prevents autophagy by interacting with Ulk1 [72]. Under nutrient-rich conditions, phosphorylation of Ulk1 by MTORC1 represses Ulk1 kinase activity and its ability to interact with Atg13 or FIP200; thereby, it coordinates the autophagy response [65,149]. In muscle cells, activation of AMPK (by AICAR treatment) or inhibition of MTORC1 (by Torin1 treatment or amino acid privation) removes AMPK, MTOR, and RPTOR from Ulk1 [139]. These events are known to induce the Ulk1-dependent phosphorylation of Atg13 and FIP200, leading to the initiation of autophagy [70].

Proteomics screens of autophagy [150] and a co-immunoprecipitation study performed in HEK293T cells [151] showed that AMPK interacts with both Ulk1 and Ulk2. In muscle cells, Ulk1 also acts as an interacting partner of AMPK, and Ser-467 site identified by Egan and colleagues is also phosphorylated by AMPK [139]. Ulk1 phosphorylation by AMPK may participate to conformational changes and thus disrupts the interaction between Ulk1 and MTORC1, in agreement with the suppression of MTORC1 anti-autophagy activity in the Ulk1 complex [72]. Moreover, Ulk1 phosphorylation by AMPK may directly activate Ulk1 kinase activity. Indeed, in vitro studies showed that Ulk1 is highly phosphorylated and that purified Ulk1 can phosphorylate itself and requires autophosphorylation for stability [152]. In mammals, Ulk1 phosphorylation by AMPK is critical for mitochondrial homeostasis and cell survival during starvation [153]. In summary, AMPK regulates Ulk1 activity by decreasing MTORC1 activity and by phosphorylating Ulk1 [121].

Inactive form

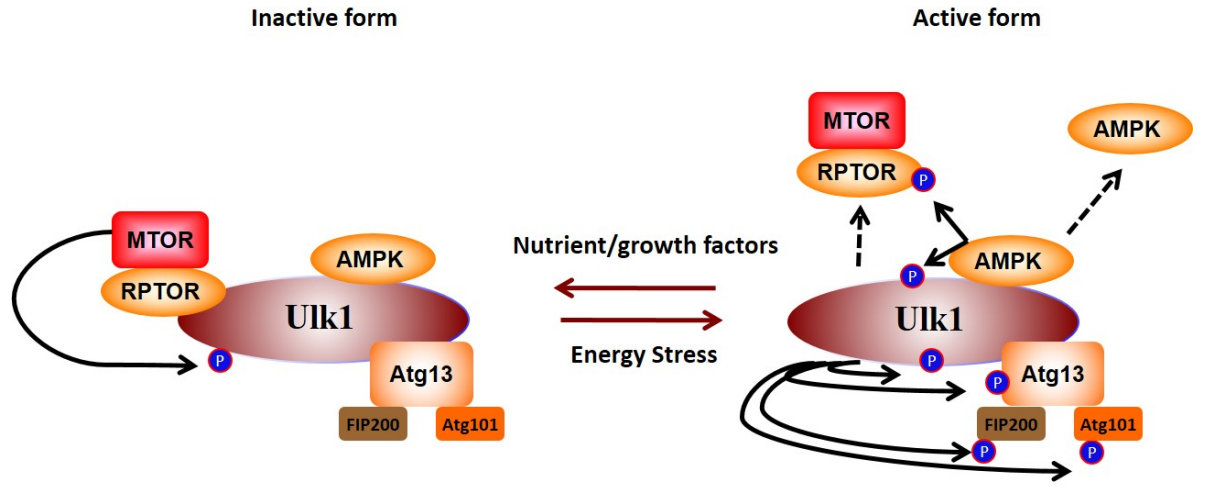

AUTOPHAGY

Figure 3. The Ulk1/Atg13/FIP200/MTORC1/AMPK complex

Time-course studies have been performed in muscle cells in order to better understand the dynamics of UlK1 complex following autophagy induction [139]. Interestingly, AMPK dissociates from Ulk1 $3 \mathrm{~h}$ after AICAR treatment [139]. In agreement with these observations, in HeLa cells, AMPK is associated with Ulk1 only under nutrient-rich condition, and it dissociates from Ulk1 5 min after starvation [154]. Thus, in normal condition, Ulk1 is associated 
with AMPK; upon AICAR treatment, the complex remains stable for $3 \mathrm{~h}$ and then dissociates. As suggested by another group, Ulk1 dissociation from AMPK could permit to Ulk1 complex to be more active [154]. Conversely, this dissociation can constitute a negative regulatory feedback as proposed by Loffler et al. [155]. The authors showed that Ulk1 could mediate phosphorylation of AMPK on the regulatory subunits, constituting an inhibitory feedback control. Further works have to define the molecular mechanisms for these events, especially in skeletal muscle.

\section{Autophagy, exercise and altitude exposure}

Attractive data concerning the role of autophagy during exercise are emerging. Autophagic vacuole formation during physical exercise was observed for the first time by Salminen and coworkers in 1984 with electron microscopy [156]. Nevertheless, there were no further studies on the topic until recently. In the last decade, data supporting the importance of autophagy in muscle homeostasis in response to exercise have been numerous, starting with a study from Bonaldo's team that showed that mice presenting impaired autophagy develop severe muscle weakness (i.e., accumulation of defective mitochondria, exacerbated apoptosis, muscle degeneration, and atrophy) [157]. Thereafter, other studies highlight that chronic inactivation of autophagy leads to a loss of metabolic effects related to exercise and drastic decreases in endurance performance [158].

Concerning autophagy modulation in response to acute exercise in humans, studies by Jamart and colleagues [159] were the first to demonstrate a raise of autophagy-regulatory genes and autophagic flux markers after ultraendurance exercise. By showing that AMPK and FoxO3a regulate in a coordinated way autophagy and ubiquitin-proteasome pathways during ultraendurance exercise, the authors gave an important picture of the cross-regulation of both degradation pathways in response to long-lasting endurance exercise [160]. Regarding more common endurance exercises, the modulation of muscle protein turnover, autophagy, and mitochondrial dynamics markers has been investigated thereafter in mice in response to different exercises conducted or not until exhaustion. Endurance exercise quickly initiates the autophagy pathway through Ulk1 activation resulting in an increase of autophagic flux, especially near exhaustion [161]. A rise in the phosphorylation of DRP1, a GTPase essential for mitochondrial fission, quickly occurred during exercise without any change in the expression of fusion markers (OPA1 and Mfn2). These data are consistent with an increase in mitophagy (i.e., the degradation of mitochondria by autophagy) since exacerbated fission can lead to mitochondrial fragmentation. Noteworthy, exercise decreases the activity of the main protein synthesis pathway (i.e., Akt/MTOR signaling pathway), from 90 min of moderate exercise (40$50 \%$ of $\mathrm{VO}_{2 \max }$ ), concomitantly to an increase in the phosphorylation of a marker of endoplasmic reticulum stress (eiF2 $\alpha$ Ser-51) [161]. Others studies reported an increase of endoplasmic reticulum stress by the evaluation of the content of the double-stranded RNA-activated protein kinase $\mathrm{R}$ (PKR)-like endoplasmic reticulum kinase (PERK), the ER stress-induced transcription factor C/EBP homologous protein (CHOP), and the X-box binding protein 1 (XBP1s), in response to both ultraendurance [162] and moderate-intensity exercise [163]. However, 
reticulophagy has not been studied yet in skeletal muscle, especially in response to exercise. Further works are needed to clarify the possible clearance of important organelles, such as ribosomes or endoplasmic reticulum, during physical exercise. Exercise promotes better "cell health"; it would be not surprising to discover that exercise increases the turnover of such organelles like it is strongly suggested for mitochondria [21].

The rise of autophagy is essential to prevent mitochondrial damage during endurance exercise. Although acute inhibition of autophagy prior to exercise seems to not significantly affect performance, it leads to accumulation of dysfunctional mitochondria and augmentation of oxidative stress especially during eccentric contraction [164]. Thus, autophagy has a critical role in mitochondria quality control during acute exercise. In addition, autophagy is highly involved in exercise training-induced adaptations. Autophagy-deficient mice present attenuated improvement of endurance capacity in response to endurance training. In parallel to lower increases of basal autophagy flux, these mice show attenuated raises of mitochondrial content and angiogenesis [165], explaining the poor response to the training program.

The dietary factors have to be considered in autophagy response to acute exercise since essential amino acids (EAA) or carbohydrate $(\mathrm{CHO})$ intake modulate protein turnover. Jamart et al. (2014) found that exercise performed in the fasted state permits a higher raise in autophagic flux indexes compared with the fed state. Concerning resistance exercise, few works showed a depression of autophagy markers after such an exercise like the study by Fry et al. conducted in humans [166]. In addition, autophagic flux markers can be depressed following EAA and carbohydrate ( $\mathrm{CHO})$ ingestion after resistance exercise [167]. To date, autophagy seems non-critical for muscle adaptations to resistance training [161]. However, an exception occurs during aging in which both endurance and resistance training are able to reverse the drop of autophagy regulatory proteins that occurs [168,169] (Fig.4).

Little is known regarding protein turnover pathways, especially autophagy, in response to exercise performed during altitude exposure in humans. Such an environment can induce a state of hypoxia that is exacerbated according to the level of altitude considered. Hypoxia results in decreased oxygen availability and leads to several hormonal, cardiorespiratory, and muscular adjustments in order to preserve cell homeostasis. Long-lasting hypoxia can cause a diminution of skeletal muscle mass and a reduction of muscle oxidative capacity. In agreement with an alteration of protein synthesis flux, hypoxia impairs the overload-induced increase of the PI3K/Akt/MTOR signaling pathway in rats [170]. Regarding degradation pathways in humans, while ubiquitin-proteasome system seems not positively modulated by environmental hypoxia, an upregulation of skeletal muscle autophagic flux markers has been found during acute normobaric hypoxia $\left(10.7 \% \mathrm{O}_{2}\right)$ and after exercise conducted in such an environment [171,172]. Another study investigated the effects of acute high-altitude exposure (at 5,300 m altitude) in the course of the Caudwell Research Expedition to Mt. Everest [173]. The authors notably found an upregulation of heat shock cognate $71 \mathrm{kDa}$ protein involved in chaperone-mediated autophagy and a reduction of protein translation markers. Taken together, these studies seem to highlight a preventive role of autophagy for energy expenditure and an activation of chaperone-mediated autophagy during acute high-altitude exposure. However, the effects of chronic altitude exposure on autophagy and its combination with training remain to be characterized to date. Chronic hypoxia leads to a change in oxidative 


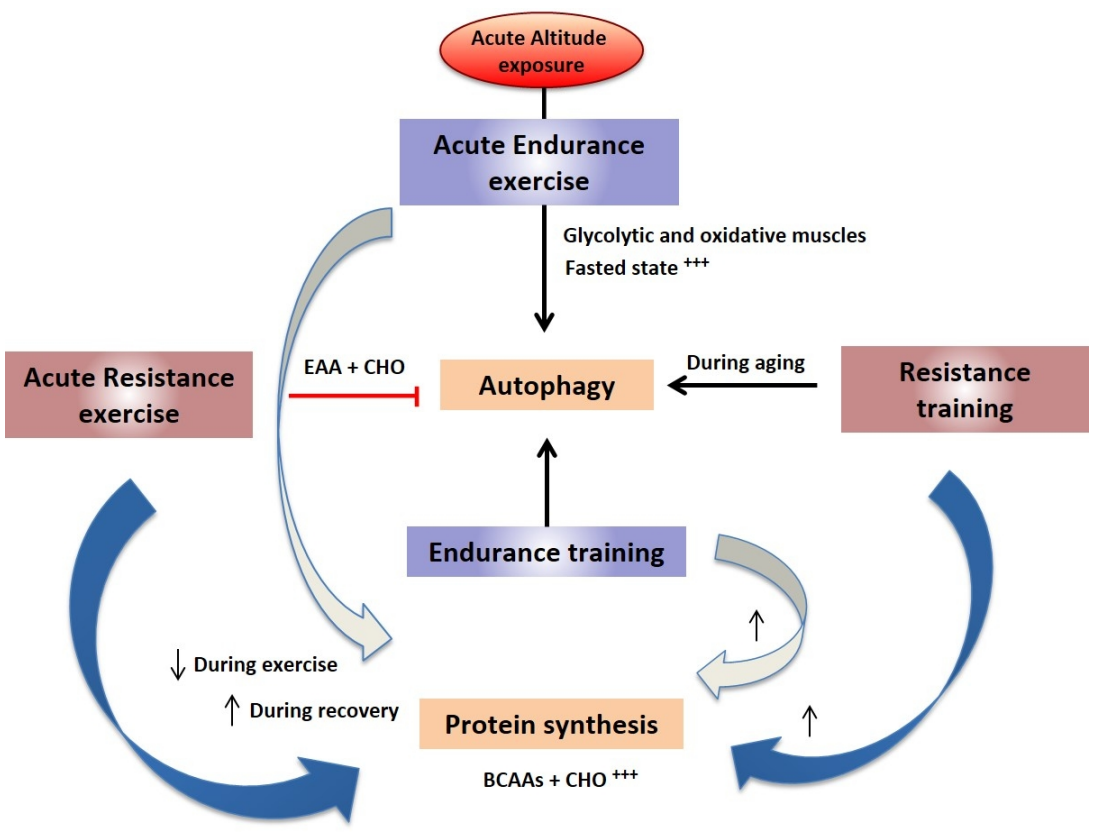

Figure 4. Exercise and autophagy in skeletal muscle. Adapted from Sanchez AMJ et al. 2014. Autophagy is essential to support skeletal muscle plasticity in response to endurance exercise. American Journal of Physiology - Regulatory, Integrative and Comparative Physiology 307(8): R956-R969 [21]. Essential amino acids (EAA); carbohydrate (CHO)

metabolism [174,175]; it is likely that autophagy, especially mitochondrial autophagy, be amended during such an exposure. Consistent with this, experiments performed in cells showed that mitochondrial autophagy is induced by chronic hypoxia through HIF-1 (hypoxiadependent factor-1) and BNIP3, and this regulation constitutes a preventive response that is necessary to avoid accumulation of reactive oxygen species and cell death [176]. The effects of exposition to moderate altitude (i.e., 1,500-3,000 m) have also to be definite since it concerns a larger population (athletes, general tourist population, and highlanders) compared to high altitude.

Research of this type is leading to a better understanding of the autophagy-mediated turnover of organelles like mitochondria in response to exercise and altitude exposure. Finding optimal training strategies represents an important objective to enhance exercise adaptations in both athletes and patients with metabolic or muscle diseases, including COPD (chronic obstructive pulmonary disease) that can cause systemic hypoxia and loss in muscle capability.

\section{Conclusions}

In summary, autophagy represents a crucial mechanism for cell homeostasis and cell survival. Autophagy constitutes a recycling process that degrades used or flawed internal structures 
into amino acid, enabling cells to survive in difficult circumstances. The identification of Ulk1 as a direct target of AMPK represents a significant step toward understanding how cellular energy stress regulates autophagy machinery in muscle cells. Based on the data presented here, it is clearly conceivable that the autophagy pathway must be considered in muscle pathologies such as sarcopenia and myopathies. Fine molecular studies on AMPK/FoxO3a and AMPK/ Ulk1 axes will offer new and promising strategies in the treatment of muscular loss associated not only to several pathologies like cancer, AIDS, and neuromuscular diseases but also to agerelated disorders. Further investigations must be conducted in order to better understand whether exercise-induced autophagy can also prevent skeletal muscle diseases. In addition, autophagy is involved in skeletal muscle adaptation to endurance exercise in a healthy population. While autophagy is important to prevent mitochondria alteration and exacerbated oxidative stress in response to severe acute exercise, its role in the improvement of endurance capacity has also been demonstrated in response to endurance training. In addition, the feeding pattern and the environment, especially altitude exposure, have to be considered since they represent additional modulators of protein turnover and autophagy pathway. Regular exercise is associated with an enhanced quality of life and represents the most profitable way to limit metabolic disorders and the loss of muscle mass. As a result, these research directions are of major interest in the battle against a wide range of diseases and have to be sustained.

\section{List of abbreviations}

4E-BP1, eukaryotic translation initiation factor 4E-binding protein $1 ; \mathrm{A} \beta$, amyloid $\beta$; AIDS, acquired immune deficiency syndrome; AMPK, 5'-adenosine monophosphate-activated protein kinase; Atg, autophagy-specific gene; BCL2, B-cell lymphoma 2; BNIP3, BCL2/ adenovirus E1B 19 kDa-interacting protein-3; CaMKK, $\mathrm{Ca}^{2+} /$ calmodulin-dependent protein kinase; $\mathrm{CHO}$, carbohydrate; $\mathrm{CHOP}, \mathrm{C} / \mathrm{EBP}$ homologous protein; $\mathrm{CMA}$, chaperone-mediated autophagy; COPD, chronic obstructive pulmonary disease; DEPTOR, DEP domain-containing MTOR-interacting protein; EAA, essential amino acids; eIF2B, eukaryotic translation initiation factor 2B; eIF2 $\alpha$, eukaryotic initiation factor $2 \alpha$; FIP200, focal adhesion kinase (FAK) familyinteracting protein of $200 \mathrm{kDa}$; FoxO, forkhead box class "other" O; Gabarapl1, GABA receptor-associated protein-like 1; GATE-16, Golgi-associated ATPase enhancer; GSK3 $\beta$, glycogen synthase kinase $3 \beta$; hsc73, heat-shock cognate protein of $73 \mathrm{kDa}$; HIF-1, hypoxiadependent factor-1; IGF-1, insulin-like growth factor-1; LAMP-2A, lysosome-associated membrane protein 2A; LC3, microtubule-associated protein 1A/ 1B light chain 3; LKB1, liver kinase B1; MAFbx/atrogin-1, muscle atrophy F-box; Mfn2, mitofusin-2; mLST8/G $\beta L$, MTORassociated protein LST8 homolog; MTOR, mechanistic/mammalian target of rapamycin; MTORC1, mechanistic/mammalian target of rapamycin complex 1; Mul1, mitochondrial E3 ubiquitin protein ligase 1; MuRF1, muscle RING-finger protein-1; OPA1, optic atrophy 1; p62/ SQSTM1, sequestosome 1; PDK1, phosphoinositide-dependent kinase-1; PE, phosphatidylethanolamine; PERK, double-stranded RNA-activated protein kinase R (PKR)-like endoplasmic reticulum kinase; PGC-1, peroxisome proliferator activator receptor $\gamma$ coactivator-1; PI3K, phosphatidylinositol 3-kinase; PINK1, PTEN-induced putative kinase protein 1; PKB/Akt, 
protein kinase B; PPAR $\alpha$, peroxisome proliferator-activated receptor $\alpha$; PRAS40, proline-rich Akt substrate of $40 \mathrm{kDa}$; PTEN, phosphatase and tensin homolog; Rheb, ras homologous enriched in brain; RPTOR, regulatory-associated protein of MTOR, complex 1; ROS, reactive oxygen species; S6K1, p70S6 kinase 1; TAK-1, transforming growth factor $\beta$-activated kinase 1; Trim32, tripartite motif-containing protein 32; TSC21/2, tuberous sclerosis complex 1/2; Ulk, unc-51-like kinase; Vps34, vacuolar protein sorting 34; XBP1s, X-box binding protein 1; ZNF216, zinc-finger protein 216

\section{Acknowledgements}

Dr AMJ Sanchez thanks the "Cité de l'excellence sportive Sud de France" of Font-Romeu (France). This work was supported by the department PHASE from INRA and by the Université de Montpellier 1, Faculté des Sciences du Sport. Miss A. Raibon holds a graduate fellowship from INRA, from the region Languedoc-Roussillon, and from INCA. The authors also thank Pr Raviola for the helpful discussions.

\section{Author details}

Anthony M.J. Sanchez ${ }^{1 *}$, Robin Candau ${ }^{2}$, Audrey Raibon ${ }^{2}$ and Henri Bernardi ${ }^{2}$

*Address all correspondence to: anthony.sanchez@univ-perp.fr

1 Laboratoire Européen Performance Santé Altitude, EA4604, Université de Perpignan Via Domitia, Département STAPS Font-Romeu, France

2 INRA, UMR866, Dynamique Musculaire et Métabolisme, Université de Montpellier, Montpellier, France

\section{References}

[1] Glass DJ (2005) Skeletal muscle hypertrophy and atrophy signaling pathways. Int J Biochem Cell Biol 37: 1974-1984.

[2] Ma XM, Blenis J (2009) Molecular mechanisms of mTOR-mediated translational control. Nat Rev Mol Cell Biol 10: 307-318.

[3] Wullschleger S, Loewith R, Hall MN (2006) TOR signaling in growth and metabolism. Cell 124: 471-484. 
[4] Bodine SC, Stitt TN, Gonzalez M, Kline WO, Stover GL, et al. (2001) Akt/mTOR pathway is a crucial regulator of skeletal muscle hypertrophy and can prevent muscle atrophy in vivo. Nat Cell Biol 3: 1014-1019.

[5] Rommel C, Bodine SC, Clarke BA, Rossman R, Nunez L, et al. (2001) Mediation of IGF-1-induced skeletal myotube hypertrophy by PI(3)K/Akt/mTOR and PI(3)K/Akt/ GSK3 pathways. Nat Cell Biol 3: 1009-1013.

[6] Sanchez AM, Csibi A, Raibon A, Docquier A, Lagirand-Cantaloube J, et al. (2013) eIF3f: a central regulator of the antagonism atrophy/hypertrophy in skeletal muscle. Int J Biochem Cell Biol 45: 2158-2162.

[7] Csibi A, Cornille K, Leibovitch MP, Poupon A, Tintignac LA, et al. (2010) The translation regulatory subunit eIF3f controls the kinase-dependent mTOR signaling required for muscle differentiation and hypertrophy in mouse. PLoS One 5: e8994.

[8] Castro AF, Rebhun JF, Clark GJ, Quilliam LA (2003) Rheb binds tuberous sclerosis complex 2 (TSC2) and promotes $S 6$ kinase activation in a rapamycin- and farnesylation-dependent manner. J Biol Chem 278: 32493-32496.

[9] Garami A, Zwartkruis FJ, Nobukuni T, Joaquin M, Roccio M, et al. (2003) Insulin activation of Rheb, a mediator of mTOR/S6K/4E-BP signaling, is inhibited by TSC1 and 2. Mol Cell 11: 1457-1466.

[10] Inoki K, Zhu T, Guan KL (2003) TSC2 mediates cellular energy response to control cell growth and survival. Cell 115: 577-590.

[11] Jefferson LS, Fabian JR, Kimball SR (1999) Glycogen synthase kinase-3 is the predominant insulin-regulated eukaryotic initiation factor 2B kinase in skeletal muscle. Int J Biochem Cell Biol 31: 191-200.

[12] Sacheck JM, Hyatt JP, Raffaello A, Jagoe RT, Roy RR, et al. (2007) Rapid disuse and denervation atrophy involve transcriptional changes similar to those of muscle wasting during systemic diseases. FASEB J 21: 140-155.

[13] Bodine SC, Latres E, Baumhueter S, Lai VK, Nunez L, et al. (2001) Identification of ubiquitin ligases required for skeletal muscle atrophy. Science 294: 1704-1708.

[14] Gomes MD, Lecker SH, Jagoe RT, Navon A, Goldberg AL (2001) Atrogin-1, a musclespecific F-box protein highly expressed during muscle atrophy. Proc Natl Acad Sci USA 98: 14440-14445.

[15] Hishiya A, Iemura S, Natsume T, Takayama S, Ikeda K, et al. (2006) A novel ubiquitin-binding protein ZNF216 functioning in muscle atrophy. EMBO J 25: 554-564.

[16] Lokireddy S, Wijesoma IW, Teng S, Bonala S, Gluckman PD, et al. (2012) The ubiquitin ligase Mul1 induces mitophagy in skeletal muscle in response to muscle-wasting stimuli. Cell Metab 16: 613-624. 
[17] Cohen S, Zhai B, Gygi SP, Goldberg AL (2012) Ubiquitylation by Trim32 causes coupled loss of desmin, Z-bands, and thin filaments in muscle atrophy. J Cell Biol 198: 575-589.

[18] Codogno P, Meijer AJ (2005) Autophagy and signaling: their role in cell survival and cell death. Cell Death Differ 12 Suppl 2: 1509-1518.

[19] Korolchuk VI, Mansilla A, Menzies FM, Rubinsztein DC (2009) Autophagy inhibition compromises degradation of ubiquitin-proteasome pathway substrates. Mol Cell 33: 517-527.

[20] Lamark T, Johansen T (2010) Autophagy: links with the proteasome. Curr Opin Cell Biol 22: 192-198.

[21] Sanchez AM, Bernardi H, Py G, Candau RB (2014) Autophagy is essential to support skeletal muscle plasticity in response to endurance exercise. Am J Physiol Regul Integr Comp Physiol 307: R956-969.

[22] Kuma A, Hatano M, Matsui M, Yamamoto A, Nakaya H, et al. (2004) The role of autophagy during the early neonatal starvation period. Nature 432: 1032-1036.

[23] Tolkovsky AM (2009) Mitophagy. Biochim Biophys Acta 1793: 1508-1515.

[24] Dunn WA, Jr., Cregg JM, Kiel JA, Van der Klei IJ, Oku M, et al. (2005) Pexophagy: the selective autophagy of peroxisomes. Autophagy 1: 75-83.

[25] Knodler LA, Celli J (2011) Eating the strangers within: host control of intracellular bacteria via xenophagy. Cell Microbiol 13: 1319-1327.

[26] Tasdemir E, Maiuri MC, Tajeddine N, Vitale I, Criollo A, et al. (2007) Cell cycle-dependent induction of autophagy, mitophagy and reticulophagy. Cell Cycle 6: 2263-2267.

[27] MacIntosh GC, Bassham DC (2011) The connection between ribophagy, autophagy and ribosomal RNA decay. Autophagy 7: 662-663.

[28] Marzella L, Ahlberg J, Glaumann H (1981) Autophagy, heterophagy, microautophagy and crinophagy as the means for intracellular degradation. Virchows Arch B Cell Pathol Incl Mol Pathol 36: 219-234.

[29] Weidberg H, Shvets E, Elazar Z (2009) Lipophagy: selective catabolism designed for lipids. Dev Cell 16: 628-630.

[30] Matsuda N, Sato S, Shiba K, Okatsu K, Saisho K, et al. (2010) PINK1 stabilized by mitochondrial depolarization recruits Parkin to damaged mitochondria and activates latent Parkin for mitophagy. J Cell Biol 189: 211-221.

[31] Vives-Bauza C, Zhou C, Huang Y, Cui M, De Vries RL, et al. (2010) PINK1-dependent recruitment of Parkin to mitochondria in mitophagy. Proc Natl Acad Sci USA 107: 378-383. 
[32] Kondapalli C, Kazlauskaite A, Zhang N, Woodroof HI, Campbell DG, et al. (2012) PINK1 is activated by mitochondrial membrane potential depolarization and stimulates Parkin E3 ligase activity by phosphorylating Serine 65. Open Biol 2: 120080.

[33] Braschi E, Zunino R, McBride HM (2009) MAPL is a new mitochondrial SUMO E3 ligase that regulates mitochondrial fission. EMBO Rep 10: 748-754.

[34] Mizushima N, Levine B, Cuervo AM, Klionsky DJ (2008) Autophagy fights disease through cellular self-digestion. Nature 451: 1069-1075.

[35] Bechet D, Tassa A, Taillandier D, Combaret L, Attaix D (2005) Lysosomal proteolysis in skeletal muscle. Int J Biochem Cell Biol 37: 2098-2114.

[36] Taillandier D, Aurousseau E, Meynial-Denis D, Bechet D, Ferrara M, et al. (1996) Coordinate activation of lysosomal, Ca 2+-activated and ATP-ubiquitin-dependent proteinases in the unweighted rat soleus muscle. Biochem J 316 (Pt 1): 65-72.

[37] Bechet DM, Deval C, Robelin J, Ferrara MJ, Obled A (1996) Developmental control of cathepsin B expression in bovine fetal muscles. Arch Biochem Biophys 334: 362-368.

[38] Belkhou R, Bechet D, Cherel Y, Galluser M, Ferrara M, et al. (1994) Effect of fasting and thyroidectomy on cysteine proteinase activities in liver and muscle. Biochim Biophys Acta 1199: 195-201.

[39] Kominami E, Tsukahara T, Bando Y, Katunuma N (1985) Distribution of cathepsins B and $\mathrm{H}$ in rat tissues and peripheral blood cells. J Biochem 98: 87-93.

[40] Kirschke H, Wood L, Roisen FJ, Bird JW (1983) Activity of lysosomal cysteine proteinase during differentiation of rat skeletal muscle. Biochem J 214: 871-877.

[41] Bechet DM, Ferrara MJ, Mordier SB, Roux MP, Deval CD, et al. (1991) Expression of lysosomal cathepsin B during calf myoblast-myotube differentiation. Characterization of a cDNA encoding bovine cathepsin B. J Biol Chem 266: 14104-14112.

[42] Ferrara M, Wojcik F, Rhaissi H, Mordier S, Roux MP, et al. (1990) Gene structure of mouse cathepsin B. FEBS Lett 273: 195-199.

[43] Gogos JA, Thompson R, Lowry W, Sloane BF, Weintraub H, et al. (1996) Gene trapping in differentiating cell lines: regulation of the lysosomal protease cathepsin $B$ in skeletal myoblast growth and fusion. J Cell Biol 134: 837-847.

[44] Jane DT, DaSilva L, Koblinski J, Horwitz M, Sloane BF, et al. (2002) Evidence for the involvement of cathepsin B in skeletal myoblast differentiation. J Cell Biochem 84: 520-531.

[45] Mordier S, Bechet D, Roux MP, Obled A, Ferrara M (1993) Nucleotide sequence of bovine preprocathepsin B. A study of polymorphism in the protein coding region. Biochim Biophys Acta 1174: 305-311. 
[46] Rhaissi H, Bechet D, Ferrara M (1993) Multiple leader sequences for mouse cathepsin B mRNA? Biochimie 75: 899-904.

[47] Jagoe RT, Lecker SH, Gomes M, Goldberg AL (2002) Patterns of gene expression in atrophying skeletal muscles: response to food deprivation. FASEB J 16: 1697-1712.

[48] Deval C, Mordier S, Obled C, Bechet D, Combaret L, et al. (2001) Identification of cathepsin $\mathrm{L}$ as a differentially expressed message associated with skeletal muscle wasting. Biochem J 360: 143-150.

[49] Lecker SH, Jagoe RT, Gilbert A, Gomes M, Baracos V, et al. (2004) Multiple types of skeletal muscle atrophy involve a common program of changes in gene expression. FASEB J 18: 39-51.

[50] Whitaker JN, Bertorini TE, Mendell JR (1983) Immunocytochemical studies of cathepsin D in human skeletal muscle. Ann Neurol 13: 133-142.

[51] Li W, Yang Q, Mao Z (2011) Chaperone-mediated autophagy: machinery, regulation and biological consequences. Cell Mol Life Sci 68: 749-763.

[52] Kon M, Cuervo AM (2010) Chaperone-mediated autophagy in health and disease. FEBS Lett 584: 1399-1404.

[53] Cuervo AM (2010) Chaperone-mediated autophagy: selectivity pays off. Trends Endocrinol Metab 21: 142-150.

[54] Agarraberes FA, Dice JF (2001) A molecular chaperone complex at the lysosomal membrane is required for protein translocation. J Cell Sci 114: 2491-2499.

[55] Kaushik S, Cuervo AM (2009) Methods to monitor chaperone-mediated autophagy. Methods Enzymol 452: 297-324.

[56] Kaushik S, Cuervo AM (2008) Chaperone-mediated autophagy. Methods Mol Biol 445: 227-244.

[57] Kaushik S, Massey AC, Mizushima N, Cuervo AM (2008) Constitutive activation of chaperone-mediated autophagy in cells with impaired macroautophagy. Mol Biol Cell 19: 2179-2192.

[58] Wing SS, Chiang HL, Goldberg AL, Dice JF (1991) Proteins containing peptide sequences related to Lys-Phe-Glu-Arg-Gln are selectively depleted in liver and heart, but not skeletal muscle, of fasted rats. Biochem J 275 (Pt 1): 165-169.

[59] Danon MJ, Oh SJ, DiMauro S, Manaligod JR, Eastwood A, et al. (1981) Lysosomal glycogen storage disease with normal acid maltase. Neurology 31: 51-57.

[60] Nishino I, Fu J, Tanji K, Yamada T, Shimojo S, et al. (2000) Primary LAMP-2 deficiency causes $\mathrm{X}$-linked vacuolar cardiomyopathy and myopathy (Danon disease). Nature 406: 906-910. 
[61] Yen WL, Klionsky DJ (2008) How to live long and prosper: autophagy, mitochondria, and aging. Physiology (Bethesda) 23: 248-262.

[62] Mizushima N, Yamamoto A, Matsui M, Yoshimori T, Ohsumi Y (2004) In vivo analysis of autophagy in response to nutrient starvation using transgenic mice expressing a fluorescent autophagosome marker. Mol Biol Cell 15: 1101-1111.

[63] Mammucari C, Milan G, Romanello V, Masiero E, Rudolf R, et al. (2007) FoxO3 controls autophagy in skeletal muscle in vivo. Cell Metab 6: 458-471.

[64] Zhao J, Brault JJ, Schild A, Cao P, Sandri M, et al. (2007) FoxO3 coordinately activates protein degradation by the autophagic/lysosomal and proteasomal pathways in atrophying muscle cells. Cell Metab 6: 472-483.

[65] Ganley IG, Lam du H, Wang J, Ding X, Chen S, et al. (2009) ULK1.ATG13.FIP200 complex mediates mTOR signaling and is essential for autophagy. J Biol Chem 284: 12297-12305.

[66] Mizushima N (2010) The role of the Atg1/ULK1 complex in autophagy regulation. Curr Opin Cell Biol 22: 132-139.

[67] Kihara A, Noda T, Ishihara N, Ohsumi Y (2001) Two distinct Vps34 phosphatidylinositol 3-kinase complexes function in autophagy and carboxypeptidase $\mathrm{Y}$ sorting in Saccharomyces cerevisiae. J Cell Biol 152: 519-530.

[68] Tassa A, Roux MP, Attaix D, Bechet DM (2003) Class III phosphoinositide 3-kinase-Beclin1 complex mediates the amino acid-dependent regulation of autophagy in C2C12 myotubes. Biochem J 376: 577-586.

[69] Russell RC, Tian Y, Yuan H, Park HW, Chang YY, et al. (2013) ULK1 induces autophagy by phosphorylating Beclin-1 and activating VPS34 lipid kinase. Nat Cell Biol 15: 741-750.

[70] Jung CH, Jun CB, Ro SH, Kim YM, Otto NM, et al. (2009) ULK-Atg13-FIP200 complexes mediate mTOR signaling to the autophagy machinery. Mol Biol Cell 20: 1992-2003.

[71] Jung CH, Ro SH, Cao J, Otto NM, Kim DH (2010) mTOR regulation of autophagy. FEBS Lett 584: 1287-1295.

[72] Hosokawa N, Hara T, Kaizuka T, Kishi C, Takamura A, et al. (2009) Nutrient-dependent mTORC1 association with the ULK1-Atg13-FIP200 complex required for autophagy. Mol Biol Cell 20: 1981-1991.

[73] Kim J, Kundu M, Viollet B, Guan KL (2011) AMPK and mTOR regulate autophagy through direct phosphorylation of Ulk1. Nat Cell Biol 13: 132-141.

[74] Kabeya Y, Mizushima N, Ueno T, Yamamoto A, Kirisako T, et al. (2000) LC3, a mammalian homologue of yeast Apg8p, is localized in autophagosome membranes after processing. EMBO J 19: 5720-5728. 
[75] Tanida I, Ueno T, Kominami E (2008) LC3 and Autophagy. Methods Mol Biol 445: 77-88.

[76] Klionsky DJ, Abdalla FC, Abeliovich H, Abraham RT, Acevedo-Arozena A, et al. (2012) Guidelines for the use and interpretation of assays for monitoring autophagy. Autophagy 8: 445-544.

[77] Bjorkoy G, Lamark T, Brech A, Outzen H, Perander M, et al. (2005) p62/SQSTM1 forms protein aggregates degraded by autophagy and has a protective effect on huntingtin-induced cell death. J Cell Biol 171: 603-614.

[78] Walczak M, Martens S (2013) Dissecting the role of the Atg12-Atg5-Atg16 complex during autophagosome formation. Autophagy 9: 424-425.

[79] Mizushima N (2005) The pleiotropic role of autophagy: from protein metabolism to bactericide. Cell Death Differ 12 Suppl 2: 1535-1541.

[80] Komatsu M, Ueno T, Waguri S, Uchiyama Y, Kominami E, et al. (2007) Constitutive autophagy: vital role in clearance of unfavorable proteins in neurons. Cell Death Differ 14: 887-894.

[81] Vainshtein A, Grumati P, Sandri M, Bonaldo P (2014) Skeletal muscle, autophagy, and physical activity: the menage a trois of metabolic regulation in health and disease. J Mol Med (Berl) 92: 127-137.

[82] Cadwell K, Liu JY, Brown SL, Miyoshi H, Loh J, et al. (2008) A key role for autophagy and the autophagy gene Atg1611 in mouse and human intestinal Paneth cells. Nature 456: 259-263.

[83] Ebato C, Uchida T, Arakawa M, Komatsu M, Ueno T, et al. (2008) Autophagy is important in islet homeostasis and compensatory increase of beta cell mass in response to high-fat diet. Cell Metab 8: 325-332.

[84] Hara T, Nakamura K, Matsui M, Yamamoto A, Nakahara Y, et al. (2006) Suppression of basal autophagy in neural cells causes neurodegenerative disease in mice. Nature 441: 885-889.

[85] Komatsu M, Waguri S, Ueno T, Iwata J, Murata S, et al. (2005) Impairment of starvation-induced and constitutive autophagy in Atg7-deficient mice. J Cell Biol 169: 425-434.

[86] Masiero E, Agatea L, Mammucari C, Blaauw B, Loro E, et al. (2009) Autophagy is required to maintain muscle mass. Cell Metab 10: 507-515.

[87] Raben N, Hill V, Shea L, Takikita S, Baum R, et al. (2008) Suppression of autophagy in skeletal muscle uncovers the accumulation of ubiquitinated proteins and their potential role in muscle damage in Pompe disease. Hum Mol Genet 17: 3897-3908.

[88] Singh R, Xiang Y, Wang Y, Baikati K, Cuervo AM, et al. (2009) Autophagy regulates adipose mass and differentiation in mice. J Clin Invest 119: 3329-3339. 
[89] Mehrpour M, Esclatine A, Beau I, Codogno P (2010) Autophagy in health and disease. 1. Regulation and significance of autophagy: an overview. Am J Physiol Cell Physiol 298: C776-C785.

[90] Cuervo AM, Bergamini E, Brunk UT, Droge W, Ffrench M, et al. (2005) Autophagy and aging: the importance of maintaining "clean" cells. Autophagy 1: 131-140.

[91] Harrison DE, Strong R, Sharp ZD, Nelson JF, Astle CM, et al. (2009) Rapamycin fed late in life extends lifespan in genetically heterogeneous mice. Nature 460: 392-395.

[92] Hashimoto Y, Ookuma S, Nishida E (2009) Lifespan extension by suppression of autophagy genes in Caenorhabditis elegans. Genes Cells 14: 717-726.

[93] Boya P, Gonzalez-Polo RA, Casares N, Perfettini JL, Dessen P, et al. (2005) Inhibition of macroautophagy triggers apoptosis. Mol Cell Biol 25: 1025-1040.

[94] Shintani T, Klionsky DJ (2004) Autophagy in health and disease: a double-edged sword. Science 306: 990-995.

[95] Levine B, Kroemer G (2008) Autophagy in the pathogenesis of disease. Cell 132: $27-42$.

[96] Tzelepis F, Verway M, Daoud J, Gillard J, Hassani-Ardakani K, et al. (2015) Annexin1 regulates DC efferocytosis and cross-presentation during Mycobacterium tuberculosis infection. J Clin Invest 125: 752-768.

[97] Liang XH, Jackson S, Seaman M, Brown K, Kempkes B, et al. (1999) Induction of autophagy and inhibition of tumorigenesis by beclin 1. Nature 402: 672-676.

[98] Gozuacik D, Kimchi A (2004) Autophagy as a cell death and tumor suppressor mechanism. Oncogene 23: 2891-2906.

[99] Ogier-Denis E, Codogno P (2003) Autophagy: a barrier or an adaptive response to cancer. Biochim Biophys Acta 1603: 113-128.

[100] Cuervo AM (2004) Autophagy: in sickness and in health. Trends Cell Biol 14: 70-77.

[101] Fukuda T, Ahearn M, Roberts A, Mattaliano RJ, Zaal K, et al. (2006) Autophagy and mistargeting of therapeutic enzyme in skeletal muscle in Pompe disease. Mol Ther 14: 831-839.

[102] Fukuda T, Roberts A, Ahearn M, Zaal K, Ralston E, et al. (2006) Autophagy and lysosomes in Pompe disease. Autophagy 2: 318-320.

[103] Cheung ZH, Ip NY (2009) The emerging role of autophagy in Parkinson's disease. Mol Brain 2: 29.

[104] Williams A, Sarkar S, Cuddon P, Ttofi EK, Saiki S, et al. (2008) Novel targets for Huntington's disease in an mTOR-independent autophagy pathway. Nat Chem Biol 4: 295-305. 
[105] Moreira PI, Santos RX, Zhu X, Lee HG, Smith MA, et al. (2010) Autophagy in Alzheimer's disease. Expert Rev Neurother 10: 1209-1218.

[106] Nilsson P, Sekiguchi M, Akagi T, Izumi S, Komori T, et al. (2015) Autophagy-related protein 7 deficiency in amyloid beta (Abeta) precursor protein transgenic mice decreases abeta in the multivesicular bodies and induces abeta accumulation in the golgi. Am J Pathol 185: 305-313.

[107] Fortun J, Dunn WA, Jr., Joy S, Li J, Notterpek L (2003) Emerging role for autophagy in the removal of aggresomes in Schwann cells. J Neurosci 23: 10672-10680.

[108] Sandri M (2010) Autophagy in skeletal muscle. FEBS Lett 584: 1411-1416.

[109] Shea L, Raben N (2009) Autophagy in skeletal muscle: implications for Pompe disease. Int J Clin Pharmacol Ther 47 Suppl 1: S42-S47.

[110] Masiero E, Sandri M (2010) Autophagy inhibition induces atrophy and myopathy in adult skeletal muscles. Autophagy 6: 307-309.

[111] Sandri M (2010) Autophagy in health and disease. 3. Involvement of autophagy in muscle atrophy. Am J Physiol Cell Physiol 298: C1291-C1297.

[112] Dobrowolny G, Aucello M, Rizzuto E, Beccafico S, Mammucari C, et al. (2008) Skeletal muscle is a primary target of SOD1G93A-mediated toxicity. Cell Metab 8: 425-436.

[113] Pietri-Rouxel F, Gentil C, Vassilopoulos S, Baas D, Mouisel E, et al. (2010) DHPR alpha1S subunit controls skeletal muscle mass and morphogenesis. EMBO J 29: 643-654.

[114] Mofarrahi M, Sigala I, Guo Y, Godin R, Davis EC, et al. (2012) Autophagy and skeletal muscles in sepsis. PLoS One 7: e47265.

[115] Rahman M, Mofarrahi M, Kristof AS, Nkengfac B, Harel S, et al. (2014) Reactive oxygen species regulation of autophagy in skeletal muscles. Antioxid Redox Signal 20: 443-459.

[116] Qi Z, He Q, Ji L, Ding S (2014) Antioxidant supplement inhibits skeletal muscle constitutive autophagy rather than fasting-induced autophagy in mice. Oxid Med Cell Longev 2014: 315896.

[117] Marzetti E, Lees HA, Wohlgemuth SE, Leeuwenburgh C (2009) Sarcopenia of aging: underlying cellular mechanisms and protection by calorie restriction. Biofactors 35: 28-35.

[118] Wenz T, Rossi SG, Rotundo RL, Spiegelman BM, Moraes CT (2009) Increased muscle PGC-1alpha expression protects from sarcopenia and metabolic disease during aging. Proc Natl Acad Sci USA 106: 20405-20410.

[119] Jorgensen SB, Viollet B, Andreelli F, Frosig C, Birk JB, et al. (2004) Knockout of the alpha2 but not alpha1 5'-AMP-activated protein kinase isoform abolishes 5-aminoi- 
midazole-4-carboxamide-1-beta-4-ribofuranosidebut not contraction-induced glucose uptake in skeletal muscle. J Biol Chem 279: 1070-1079.

[120] Hawley SA, Boudeau J, Reid JL, Mustard KJ, Udd L, et al. (2003) Complexes between the LKB1 tumor suppressor, STRAD alpha/beta and MO25 alpha/beta are upstream kinases in the AMP-activated protein kinase cascade. J Biol 2: 28.

[121] Sanchez AM, Candau RB, Csibi A, Pagano AF, Raibon A, et al. (2012) The role of AMP-activated protein kinase in the coordination of skeletal muscle turnover and energy homeostasis. Am J Physiol Cell Physiol 303: C475-C485.

[122] Marsin AS, Bertrand L, Rider MH, Deprez J, Beauloye C, et al. (2000) Phosphorylation and activation of heart PFK-2 by AMPK has a role in the stimulation of glycolysis during ischaemia. Curr Biol 10: 1247-1255.

[123] Merrill GF, Kurth EJ, Hardie DG, Winder WW (1997) AICA riboside increases AMPactivated protein kinase, fatty acid oxidation, and glucose uptake in rat muscle. Am J Physiol 273: E1107-1112.

[124] Vavvas D, Apazidis A, Saha AK, Gamble J, Patel A, et al. (1997) Contraction-induced changes in acetyl-CoA carboxylase and 5'-AMP-activated kinase in skeletal muscle. J Biol Chem 272: 13255-13261.

[125] Winder WW, Hardie DG (1996) Inactivation of acetyl-CoA carboxylase and activation of AMP-activated protein kinase in muscle during exercise. Am J Physiol 270: E299-E304.

[126] Winder WW, Wilson HA, Hardie DG, Rasmussen BB, Hutber CA, et al. (1997) Phosphorylation of rat muscle acetyl-CoA carboxylase by AMP-activated protein kinase and protein kinase A. J Appl Physiol (1985) 82: 219-225.

[127] Aschenbach WG, Hirshman MF, Fujii N, Sakamoto K, Howlett KF, et al. (2002) Effect of AICAR treatment on glycogen metabolism in skeletal muscle. Diabetes 51: 567-573.

[128] Carling D, Hardie DG (1989)The substrate and sequence specificity of the AMP-activated protein kinase. Phosphorylation of glycogen synthase and phosphorylase kinase. Biochim Biophys Acta 1012: 81-86.

[129] Carling D, Clarke PR, Zammit VA, Hardie DG (1989) Purification and characterization of the AMP-activated protein kinase. Copurification of acetyl-CoA carboxylase kinase and 3-hydroxy-3-methylglutaryl-CoA reductase kinase activities. Eur J Biochem 186: 129-136.

[130] Carling D, Zammit VA, Hardie DG (1987) A common bicyclic protein kinase cascade inactivates the regulatory enzymes of fatty acid and cholesterol biosynthesis. FEBS Lett 223: 217-222. 
[131] Garton AJ, Campbell DG, Carling D, Hardie DG, Colbran RJ, et al. (1989) Phosphorylation of bovine hormone-sensitive lipase by the AMP-activated protein kinase. A possible antilipolytic mechanism. Eur J Biochem 179: 249-254.

[132] Lee WJ, Kim M, Park HS, Kim HS, Jeon MJ, et al. (2006) AMPK activation increases fatty acid oxidation in skeletal muscle by activating PPARalpha and PGC-1. Biochem Biophys Res Commun 340: 291-295.

[133] Liang H, Ward WF (2006) PGC-1alpha: a key regulator of energy metabolism. Adv Physiol Educ 30: 145-151.

[134] Derave W, Ai H, Ihlemann J, Witters LA, Kristiansen S, et al. (2000) Dissociation of AMP-activated protein kinase activation and glucose transport in contracting slowtwitch muscle. Diabetes 49: 1281-1287.

[135] Inoki K, Kim J, Guan KL (2012) AMPK and mTOR in cellular energy homeostasis and drug targets. Annu Rev Pharmacol Toxicol 52: 381-400.

[136] Mounier R, Lantier L, Leclerc J, Sotiropoulos A, Pende M, et al. (2009) Important role for AMPKalpha1 in limiting skeletal muscle cell hypertrophy. FASEB J 23: 2264-2273.

[137] Lantier L, Mounier R, Leclerc J, Pende M, Foretz M, et al. (2010) Coordinated maintenance of muscle cell size control by AMP-activated protein kinase. FASEB J 24: 3555-3561.

[138] Nakashima K, Yakabe Y (2007) AMPK activation stimulates myofibrillar protein degradation and expression of atrophy-related ubiquitin ligases by increasing FOXO transcription factors in C2C12 myotubes. Biosci Biotechnol Biochem 71: 1650-1656.

[139] Sanchez AM, Csibi A, Raibon A, Cornille K, Gay S, et al. (2012) AMPK promotes skeletal muscle autophagy through activation of forkhead FoxO3a and interaction with Ulk1. J Cell Biochem 113: 695-710.

[140] Sanchez AM, Candau RB, Bernardi H (2014) FoxO transcription factors: their roles in the maintenance of skeletal muscle homeostasis. Cell Mol Life Sci 71: 1657-1671.

[141] Slopack D, Roudier E, Liu ST, Nwadozi E, Birot O, et al. (2014) Forkhead BoxO transcription factors restrain exercise-induced angiogenesis. J Physiol 592: 4069-4082.

[142] Sanchez AM (2015) FoxO transcription factors and endurance training: a role for FoxO1 and FoxO3 in exercise-induced angiogenesis. J Physiol 593: 363-364.

[143] Greer EL, Oskoui PR, Banko MR, Maniar JM, Gygi MP, et al. (2007) The energy sensor AMP-activated protein kinase directly regulates the mammalian FOXO3 transcription factor. J Biol Chem 282: 30107-30119.

[144] Juhasz G, Puskas LG, Komonyi O, Erdi B, Maroy P, et al. (2007) Gene expression profiling identifies FKBP39 as an inhibitor of autophagy in larval Drosophila fat body. Cell Death Differ 14: 1181-1190. 
[145] Sengupta A, Molkentin JD, Yutzey KE (2009) FoxO transcription factors promote autophagy in cardiomyocytes. J Biol Chem 284: 28319-28331.

[146] Liu HY, Han J, Cao SY, Hong T, Zhuo D, et al. (2009) Hepatic autophagy is suppressed in the presence of insulin resistance and hyperinsulinemia: inhibition of FoxO1-dependent expression of key autophagy genes by insulin. J Biol Chem 284: 31484-31492.

[147] Chiacchiera F, Matrone A, Ferrari E, Ingravallo G, Lo Sasso G, et al. (2009) p38alpha blockade inhibits colorectal cancer growth in vivo by inducing a switch from HIF1alpha- to FoxO-dependent transcription. Cell Death Differ 16: 1203-1214.

[148] Tong JF, Yan X, Zhu MJ, Du M (2009) AMP-activated protein kinase enhances the expression of muscle-specific ubiquitin ligases despite its activation of IGF-1/Akt signaling in C2C12 myotubes. J Cell Biochem 108: 458-468.

[149] Hara T, Mizushima N (2009) Role of ULK-FIP200 complex in mammalian autophagy: FIP200, a counterpart of yeast Atg17? Autophagy 5: 85-87.

[150] Behrends C, Sowa ME, Gygi SP, Harper JW (2010) Network organization of the human autophagy system. Nature 466: 68-76.

[151] Lee JW, Park S, Takahashi Y, Wang HG (2010) The association of AMPK with ULK1 regulates autophagy. PLoS One 5: e15394.

[152] Dorsey FC, Rose KL, Coenen S, Prater SM, Cavett V, et al. (2009) Mapping the phosphorylation sites of Ulk1. J Proteome Res 8: 5253-5263.

[153] Egan DF, Shackelford DB, Mihaylova MM, Gelino S, Kohnz RA, et al. (2011) Phosphorylation of ULK1 (hATG1) by AMP-activated protein kinase connects energy sensing to mitophagy. Science 331: 456-461.

[154] Shang L, Chen S, Du F, Li S, Zhao L, et al. (2011) Nutrient starvation elicits an acute autophagic response mediated by Ulk1 dephosphorylation and its subsequent dissociation from AMPK. Proc Natl Acad Sci USA 108: 4788-4793.

[155] Loffler AS, Alers S, Dieterle AM, Keppeler H, Franz-Wachtel M, et al. (2011) Ulk1mediated phosphorylation of AMPK constitutes a negative regulatory feedback loop. Autophagy 7: 696-706.

[156] Salminen A, Vihko V (1984) Autophagic response to strenuous exercise in mouse skeletal muscle fibers. Virchows Arch B Cell Pathol Incl Mol Pathol 45: 97-106.

[157] Grumati P, Coletto L, Schiavinato A, Castagnaro S, Bertaggia E, et al. (2011) Physical exercise stimulates autophagy in normal skeletal muscles but is detrimental for collagen VI-deficient muscles. Autophagy 7: 1415-1423.

[158] He C, Bassik MC, Moresi V, Sun K, Wei Y, et al. (2012) Exercise-induced BCL2-regulated autophagy is required for muscle glucose homeostasis. Nature 481: 511-515. 
[159] Jamart C, Benoit N, Raymackers JM, Kim HJ, Kim CK, et al. (2012) Autophagy-related and autophagy-regulatory genes are induced in human muscle after ultraendurance exercise. Eur J Appl Physiol 112: 3173-3177.

[160] Jamart C, Francaux M, Millet GY, Deldicque L, Frere D, et al. (2012) Modulation of autophagy and ubiquitin-proteasome pathways during ultra-endurance running. J Appl Physiol.

[161] Pagano AF, Py G, Bernardi H, Candau RB, Sanchez AM (2014) Autophagy and protein turnover signaling in slow-twitch muscle during exercise. Med Sci Sports Exerc 46: 1314-1325.

[162] Kim HJ, Jamart C, Deldicque L, An GL, Lee YH, et al. (2011) Endoplasmic reticulum stress markers and ubiquitin-proteasome pathway activity in response to a $200-\mathrm{km}$ run. Med Sci Sports Exerc 43: 18-25.

[163] Jamart C, Naslain D, Gilson H, Francaux M (2013) Higher activation of autophagy in skeletal muscle of mice during endurance exercise in the fasted state. Am J Physiol Endocrinol Metab 305: E964-E974.

[164] LoVerso F, Carnio S, Vainshtein A, Sandri M (2014) Autophagy is not required to sustain exercise and PRKAA1/AMPK activity but is important to prevent mitochondrial damage during physical activity. Autophagy 10.

[165] Lira VA, Okutsu M, Zhang M, Greene NP, Laker RC, et al. (2013) Autophagy is required for exercise training-induced skeletal muscle adaptation and improvement of physical performance. FASEB J 27: 4184-4193.

[166] Fry CS, Drummond MJ, Glynn EL, Dickinson JM, Gundermann DM, et al. (2013) Skeletal muscle autophagy and protein breakdown following resistance exercise are similar in younger and older adults. J Gerontol A Biol Sci Med Sci 68: 599-607.

[167] Glynn EL, Fry CS, Drummond MJ, Dreyer HC, Dhanani S, et al. (2010) Muscle protein breakdown has a minor role in the protein anabolic response to essential amino acid and carbohydrate intake following resistance exercise. Am J Physiol Regul Integr Comp Physiol 299: R533-R540.

[168] Kim YA, Kim YS, Oh SL, Kim HJ, Song W (2013) Autophagic response to exercise training in skeletal muscle with age. J Physiol Biochem 69: 697-705.

[169] Luo L, Lu AM, Wang Y, Hong A, Chen Y, et al. (2013) Chronic resistance training activates autophagy and reduces apoptosis of muscle cells by modulating IGF-1 and its receptors, Akt/mTOR and Akt/FOXO3a signaling in aged rats. Exp Gerontol 48: 427-436.

[170] Chaillou T, Koulmann N, Simler N, Meunier A, Serrurier B, et al. (2012) Hypoxia transiently affects skeletal muscle hypertrophy in a functional overload model. Am J Physiol Regul Integr Comp Physiol 302: R643-654. 
[171] Masschelein E, Van Thienen R, D'Hulst G, Hespel P, Thomis M, et al. (2014) Acute environmental hypoxia induces LC3 lipidation in a genotype-dependent manner. FASEB J 28: 1022-1034.

[172] D'Hulst G, Jamart C, Van Thienen R, Hespel P, Francaux M, et al. (2013) Effect of acute environmental hypoxia on protein metabolism in human skeletal muscle. Acta Physiol (Oxf) 208: 251-264.

[173] Levett DZ, Vigano A, Capitanio D, Vasso M, De Palma S, et al. (2015) Changes in muscle proteomics in the course of the Caudwell Research Expedition to Mt. Everest. Proteomics 15: 160-171.

[174] Ferretti G (2003) Limiting factors to oxygen transport on Mount Everest 30 years after: a critique of Paolo Cerretelli's contribution to the study of altitude physiology. Eur J Appl Physiol 90: 344-350.

[175] Howald H, Hoppeler H (2003) Performing at extreme altitude: muscle cellular and subcellular adaptations. Eur J Appl Physiol 90: 360-364.

[176] Zhang H, Bosch-Marce M, Shimoda LA, Tan YS, Baek JH, et al. (2008) Mitochondrial autophagy is an HIF-1-dependent adaptive metabolic response to hypoxia. J Biol Chem 283: 10892-10903. 
